Article

\title{
Lycium Barbarum Polysaccharide-Iron (III) Chelate as Peroxidase Mimics for Total Antioxidant Capacity Assay of Fruit and Vegetable Food
}

\author{
Shuo Shi ${ }^{\dagger}$, Jianxing Feng ${ }^{\dagger}$, Yanmin Liang, Hao Sun, Xuewei Yang, Zehui Su, Linpin Luo, Jianlong Wang \\ and Wentao Zhang *(i)
}

check for

updates

Citation: Shi, S.; Feng, J.; Liang, Y.; Sun, H.; Yang, X.; Su, Z.; Luo, L.;

Wang, J.; Zhang, W. Lycium Barbarum Polysaccharide-Iron (III) Chelate as Peroxidase Mimics for Total Antioxidant Capacity Assay of Fruit and Vegetable Food. Foods 2021, 10, 2800. https://doi.org/10.3390/ foods 10112800

Academic Editor: Fani Mantzouridou

Received: 23 October 2021

Accepted: 12 November 2021

Published: 14 November 2021

Publisher's Note: MDPI stays neutral with regard to jurisdictional claims in published maps and institutional affiliations.

Copyright: (C) 2021 by the authors. Licensee MDPI, Basel, Switzerland. This article is an open access article distributed under the terms and conditions of the Creative Commons Attribution (CC BY) license (https:// creativecommons.org/licenses/by/ $4.0 /)$
College of Food Science and Engineering, Northwest A\&F University, 22 Xinong Road, Xianyang 712100, China; shishuo1025@163.com (S.S.); fengjianxing98@nwafu.edu.cn (J.F.); liangyymm@163.com (Y.L.); 15591898565@163.com (H.S.); yangxuewei@nwsuaf.edu.cn (X.Y.); suzehui0809@163.com (Z.S.); linpinluo@nwafu.edu.cn (L.L.); wanglong79@nwsuaf.edu.cn (J.W.)

* Correspondence: zhangwt@nwsuaf.edu.cn; Tel.: +86 29-8709-2275

+ These authors contributed equally to this work.

Abstract: Quantitative evaluation of the antioxidant capacity of foods is of great significance for estimating food's nutritional value and preventing oxidative changes in food. Herein, we demonstrated an easy and selective colorimetric method for the total antioxidant capacity (TAC) assay based on 3,3',5,5'-tetramethyl-benzidine (TMB), hydrogen peroxide $\left(\mathrm{H}_{2} \mathrm{O}_{2}\right)$ and synthetic Lycium barbarum polysaccharide-iron (III) chelate (LBPIC) with high peroxidase (POD)-like activity. The results of steady-state kinetics study showed that the $\mathrm{K}_{\mathrm{m}}$ values of LBPIC toward $\mathrm{H}_{2} \mathrm{O}_{2}$ and TMB were $5.54 \mathrm{mM}$ and $0.16 \mathrm{mM}$, respectively. The detection parameters were optimized, and the linear interval and limit of detection (LOD) were determined to be $2-100 \mu \mathrm{M}$ and $1.51 \mu \mathrm{M}$, respectively. Additionally, a subsequent study of the determination of TAC in six commercial fruit and vegetable beverages using the established method was successfully carried out. The results implied an expanded application of polysaccharide-iron (III) chelates with enzymatic activity in food antioxidant analysis and other biosensing fields.

Keywords: total antioxidant capacity (TAC); peroxidase; polysaccharide-iron complex; steady-state kinetics; Lycium barbarum polysaccharide (LBP)

\section{Introduction}

Reactive oxygen species (ROS) are triggers of oxidative stress (OS) in the human body, which may result in various degrees of oxidative injury to human tissues and organs [1,2]. Thus, oxidative stress mediated by excessive ROS is a noteworthy inducer of chronic diseases such as presenility, cancer, cardiovascular, and neurodegenerative diseases [3]. Fortunately, bioactive antioxidants in foods are able to not only be used as precautions against chronic illnesses but also prevent food from spoiling during storage [4]. Recently, total antioxidant capacity (TAC), a representative index of the antioxidative function of food, has been correlated with food trophic value and storage stability [5]. Analytical methods for the measurement of antioxidant capacity of food samples using large instruments, such as electron paramagnetic resonance (EPR) spectroscopy [6], attenuated total reflectance infrared spectroscopy (ATR-IR) and Raman spectroscopy, have definitely been shown to be effective [7]. However, the shortcomings of requiring expensive instruments and complicated operations limit their use. To meet the need for the rapid determination of the antioxidant capacity of samples, colorimetric methods with a rapid detection speed, low cost and simple operation have been commonly used. Specifically, previous reports have demonstrated several reliable spectrophotometric TAC methods, such as the 2,2'-diphenyl-1-picrylhydrazyl (DPPH) radical assay [8], 2,2-azinobis(3-ethylbenzothiazoline-6-sulfonate) (ABTS) radical assay [9], Folin-Ciocalteu (FC) assay 
and oxygen radical absorbance capacity (ORAC) assay [10,11]. Nevertheless, the use of serial complex chemical reactions inevitably results in the drawback of poor repeatability. Hence, the establishment of a convenient method with a high accuracy for TAC detection still needs to be explored.

In recent years, artificial mimetic enzymes with oxidase activity or peroxidase (POD)like activity, particularly nanozymes developed from functionalized metals or metal oxides, have been used to construct multifarious techniques in biosensing [12]. Inspired by the active site composition and possible catalytic mechanism of horseradish peroxidase (HRP) [13], iron-based mimic enzymes, especially iron-based nanozymes, were constructed as artificial peroxidases. According to earlier reports, nanozymes based on iron oxides such as $\mathrm{Fe}_{2} \mathrm{O}_{3}$ or $\mathrm{Fe}_{3} \mathrm{O}_{4}$ were perceived to be dependable, low cost and simple in preparation $[14,15]$. Nonetheless, the disadvantages of toxicity evoked by free radicals generated during the catalytic process, limitation for the catalytic condition and poor selectivity of iron-based nanozymes fettered their development in the area of catalysis [16]. Thus, to make iron-based nanozymes available for exploitation, strategies such as organic modification for basic iron oxide nanozymes, construction of single-atom iron nanozymes and ferrous metal-organic frameworks (MOFs) have been implemented, which enhance the catalytic properties of nanozymes or overcome certain shortcomings of toxic effects or strict catalytic conditions in applications [17-19]. However, the modification methods mentioned above are usually not only costly but also complicated to operate; hence, more efficient solutions still need to be put forward.

To establish a handy, accurate and reliable TAC assay by means of designing and synthesizing a novel artificial enzyme overcoming the major drawbacks of traditional ironbased artificial enzymes, based on the internal sheath-core structure of iron-dextran [20], we propose a distinctive strategy to synthesize a polysaccharide-iron complex as an organic modified iron-based artificial enzyme. Polysaccharides are usually considered (1) stabilizers for other materials, (2) toxicity reduction media, (3) control agents for the growth of some nanoparticles, (4) molds for specific oxide structures and (5) carriers in functional materials [21]. In this study, Lycium barbarum polysaccharide (LBP) with favorable natural activities [22] was used to chemically synthesize Lycium barbarum polysaccharide-iron (III) chelate (LBPIC) through a self-embedding process. The results of the characterization of the product demonstrated the successful synthesis of LBPIC, and the catalytic test results and study of the steady-state kinetics of LBPIC showed that to establish a new TAC assay with applicable reliability, low cost and reasonable accuracy, the prepared LBPIC was used as a peroxidase mimic, and ascorbic acid (AA) served as an antioxidant model [23]. Finally, the TAC assay was conducted to quantitatively evaluate the TAC in commercial beverages, and the results demonstrated that the proposed TAC assay had a short test time, high feasibility, accurate quantification and strong resistance to interference.

\section{Materials and Methods}

\subsection{Material and Reagents}

Crude Lycium barbarum polysaccharide was purchased from Shanghai Yuanye Bio-Technology Co., Ltd. (Shanghai, China). Graphene oxide powder was obtained from Nanjing Xianfeng NanoMaterial Technology Co. Ltd. (Nanjing, China). 3,3',5,5'Tetramethylbenzidine (TMB) and $\mathrm{NaBr}$ (FT-IR grade) were purchased from Shanghai Aladdin Biochemical Technology (Shanghai, China). $\mathrm{H}_{2} \mathrm{O}_{2}$ and ascorbic acid were obtained from Guangdong Guanghua Technology Co., Ltd. (Guangdong, China). Other reagents were all obtained locally. All experimental aqueous solutions were prepared with distilled water.

\subsection{Purification and Decoloration of Crude LBP}

Generally, crude LBP was purified using a water solution and alcohol sedimentation method. Then, the decoloration of LBP after purification was carried out using prepared 
aminated reduced graphene oxide $\left(\mathrm{NH}_{2}-\mathrm{rGO}\right)$, which was synthesized by the method of Shi et al. [24]. Specific process details are given in Section 1 of the Supplementary Material.

\subsection{Synthesis of LBPIC}

Briefly, LBPIC was synthesized based on the method used by Zhang et al. [25]. Trisodium citrate $(0.4 \mathrm{~g})$ was completely dissolved in the decolored LBP aqueous solution. $\mathrm{FeCl}_{3}(2 \mathrm{M})$ was added dropwise with continuous stirring until the solution remained turbid, and the $\mathrm{pH}$ value was adjusted to $7.0-8.0$ using $\mathrm{NaOH}(2 \mathrm{M})$. The solution was heated in a water bath at $70{ }^{\circ} \mathrm{C}$ for $1 \mathrm{~h}$. After centrifugation ( $5000 \mathrm{rpm}, 5 \mathrm{~min}$ ), the precipitate was dissolved in a small amount of water and washed with alcohol at least three times. Finally, the product was lyophilized, and LBPIC was the resulting reddish brown powder.

\subsection{Characterization of LBPIC}

The prepared LBPIC was characterized by scanning electron microscopy, FT-IR spectroscopy, X-ray diffraction and X-ray photoelectron spectroscopy. The physical properties of LBPIC and storage stability of its aqueous solution at room temperature were recorded by means of visual inspection (Section 2 of the Supplementary Material).

\subsection{Peroxidase-Like Activity of LBPIC}

Peroxidases, such as HRP, are able to catalyze $\mathrm{H}_{2} \mathrm{O}_{2}$ to produce $\bullet \mathrm{OH}$ radicals, which can oxidize colorless TMB to blue ox-TMB. In summary, the POD-like activity of LBPIC was assessed through a typical TMB color change experiment. The experimental group contained acetate buffer (0.01 M, pH 3.0), $\mathrm{H}_{2} \mathrm{O}_{2}(25 \mathrm{mM})$, TMB $(1 \mathrm{mM})$ and LBPIC $(25 \mu \mathrm{g} / \mathrm{mL})$, while the control group contained TMB and $\mathrm{H}_{2} \mathrm{O}_{2}$ or only TMB. After incubation for $5 \mathrm{~min}$ at room temperature, the absorbance of each group was measured on a UV-vis spectrophotometer (UV-2550, Shimadzu, Japan). The experiments for optimization of the reaction conditions, including $\mathrm{pH}$, temperature, and time-dependent kinetics, were conducted via the methods outlined in Section 3 of the Supplementary Material.

\subsection{Enzyme Kinetics Studies of LBPIC}

A steady-state kinetics assay was performed in acetate buffer (0.01 M, pH 3.0) by changing the concentrations of $\mathrm{H}_{2} \mathrm{O}_{2}(10-240 \mathrm{mM})$ with a fixed concentration of TMB $(1.0 \mathrm{mM})$ or changing the concentrations of TMB $(0.1-1.0 \mathrm{mM})$ while maintaining the concentration of $\mathrm{H}_{2} \mathrm{O}_{2}(25 \mathrm{mM})$. The absorbances at $652 \mathrm{~nm}$ were recorded during reactions. The initial velocity of each catalytic reaction was determined in terms of the gradient of system absorbance variation. Afterward, the data were fit with the Michaelis-Menten equation based on the initial velocities and substrate concentrations to obtain the Michaelis constants $K_{m}$ and $V_{\max }$.

\subsection{Detection of $A A$}

As a representative antioxidant, ascorbic acid can be used to establish indirect detection methods for the total antioxidant capacity of foods [26]. First, the acetate buffer solutions (0.01 M, pH 3.0) that contained $\mathrm{H}_{2} \mathrm{O}_{2}(25 \mathrm{mM})$, TMB $(1.0 \mathrm{mM})$ and LBPIC $(25 \mu \mathrm{g} / \mathrm{mL})$ were mixed with a variety of concentrations of AA $(0-100 \mu \mathrm{M})$. The absorption spectra of the systems were measured after incubation at room temperature for $180 \mathrm{~s}$ using a UV-vis spectrophotometer.

\subsection{Selectivity Test of the AA Detection Assay}

For assessing the selectivity for AA in the detection assay, some substances that commonly occur in food, including $\mathrm{Mg}^{2+}, \mathrm{Ca}^{2+}, \mathrm{Zn}^{2+}, \mathrm{K}^{+}, \mathrm{Na}^{+}$, citric acid (CA), fructose, sucrose, alanine, glutamic acid, aspartic acid, and glycine, were added in sufficient amounts into the AA detection system, with concentrations of these interference factors 20 times that of AA. The absorbances at $652 \mathrm{~nm}$ of all test groups were recorded after reaction for $180 \mathrm{~s}$ at room temperature. 


\subsection{TAC Detection in Food Samples}

The AA detection assay outlined above was validated by measuring the TAC of two vitamin $C$ tablets. Whereafter, this method was used to determine the TAC of five kinds of commercial fruit-vegetable beverages and one fermented beverage. First, the beverage sample was diluted so that the determination results could be determined from the linear range of AA detection. Afterward, the diluted samples were used in place of the AA. Hence, the absorbances of the detection system were converted into the micromolar equivalent of AA. Ultimately, combining the dilution ratio of the sample and the calculation result from the colorimetry, the TAC of the food sample was expressed in the form of AA equivalents.

\section{Results and Discussion}

\subsection{Characterization of LBPIC}

In our study, as depicted in Scheme 1a, crude LBP was amply dissolved in distilled water, filtered and precipitated with aqueous ethanol (ethanol content: $80 \%$ ) to remove multiple water-insoluble or alcohol-soluble impurities. After the separation and lyophilization of polysaccharide deposits, LBP was redissolved, and its decoloration was realized using a nondestructive method where the pigments were efficiently absorbed by prepared $\mathrm{NH}_{2}$-rGO. The decolored filtrate of LBP appeared nearly achromatous and transparent, indicating an adequate removal of pigments and impurities from crude LBP.

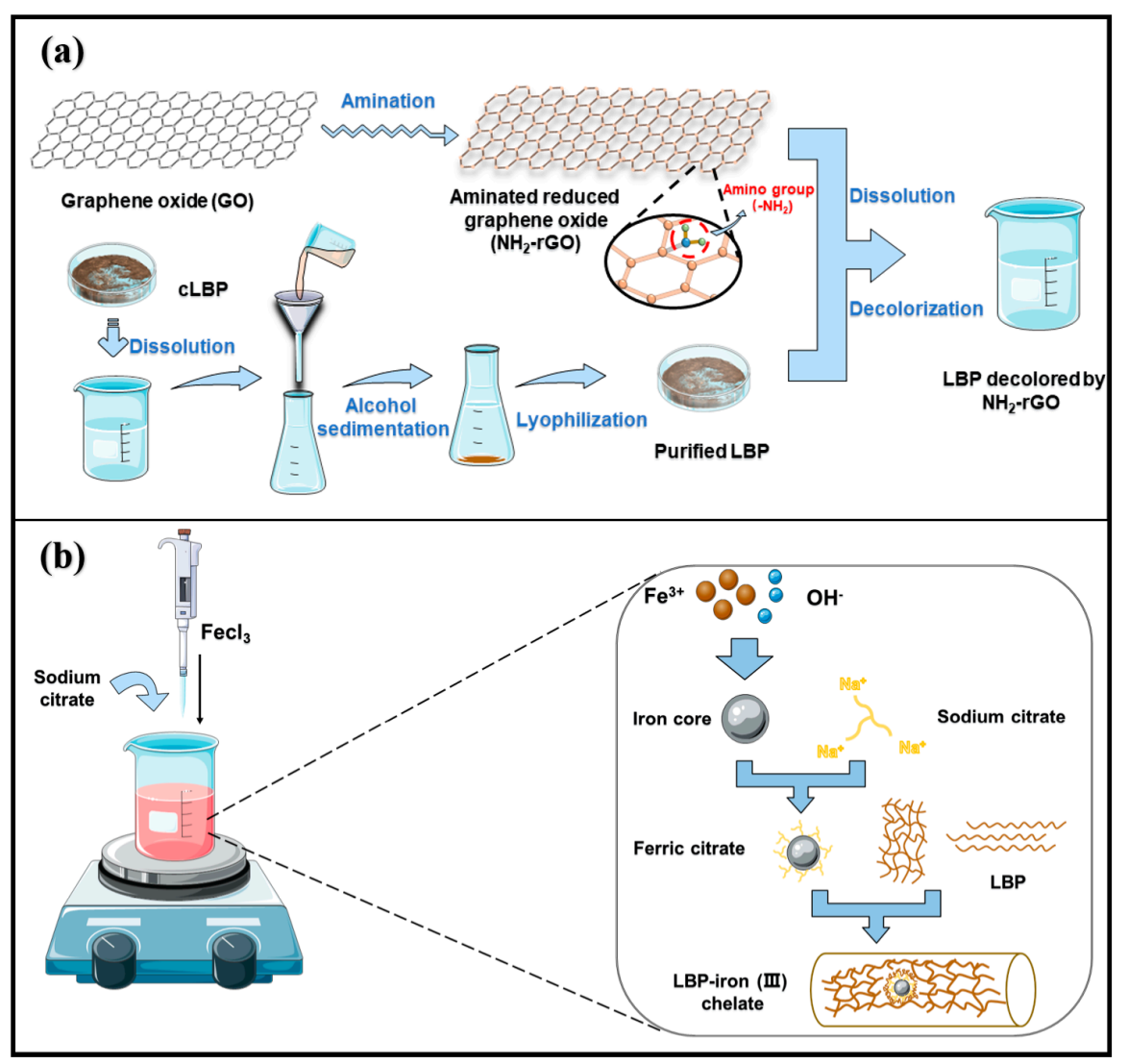

Scheme 1. Diagram of (a) preparation material Lycium barbarum polysaccharide (LBP) and (b) possible synthesis mechanism of LBPIC (Lycium barbarum polysaccharide-iron (III) chelate).

The raw material LBP aqueous solution was mixed with trisodium citrate, an effective adjuvant for the chelation reaction, to synthesize LBPIC through a self-embedding method with slight modification. Figure S1 shows that the product was a water-soluble reddish brown amorphous powder whose aqueous solutions were yellow or brown. To investigate the basic stability of LBPIC, aspects of its water solution were regularly recorded by visual inspection. As shown in Figure S2, the water solution of LBPIC $(1.0 \mathrm{mg} / \mathrm{mL})$ had a 
favorable optical stability during a one-week preservation at room temperature, which revealed the creation of a stable functional polysaccharide-iron chelation.

The possible synthesis mechanism between iron and LBP is shown in Scheme 1b. First, a polymeric iron core is formed via the polymerization of ferric ions in a mildly alkaline solution. The iron core then polymerizes with citrate ions to form a ferric citrate complex and citric acid is released during this period. Polysaccharides (LBPs) act as ligands and finally chelate ferric citrate complexes on their surface [27]. The chelating reaction between $\mathrm{LBP}$ and iron is terminated by stopping the addition of $\mathrm{FeCl}_{3}$ solution when a precipitate emerges and the system remains turbid after stirring, which indicates that the LBP material has been completely consumed to coordinate with the iron.

SEM was used to obtain detail about the morphology of LBPIC. As shown in Figure 1a, the surface of LBPIC appeared sheet-like, irregular and full of dendritic and rod-like structures, which is consistent with the study by Zhang et al. [28]. Notably, from the SEM results and possible synthesis mechanism of LBPIC, we can conclude that the ferric citrate complex was likely to be wrapped by the LBP. As a consequence, many rod-like microstructures were observed in the morphology of LBPIC, which lends credence to the aforementioned synthesis mechanism.

(a)

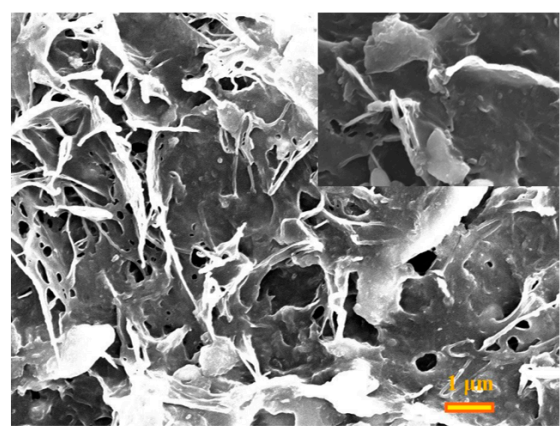

(c)

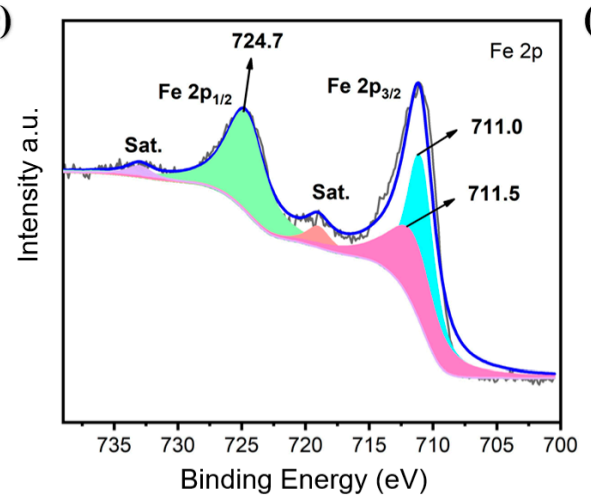

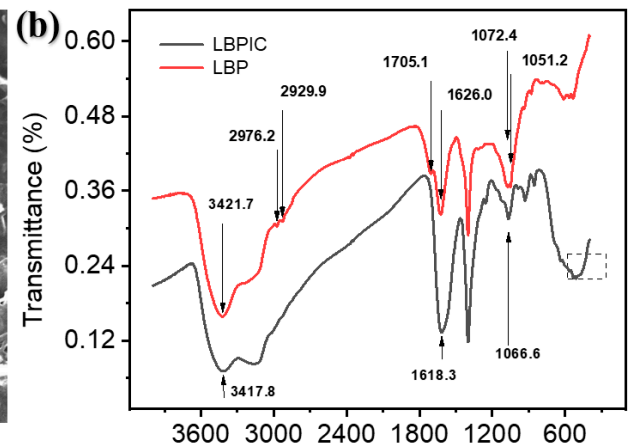

(d)

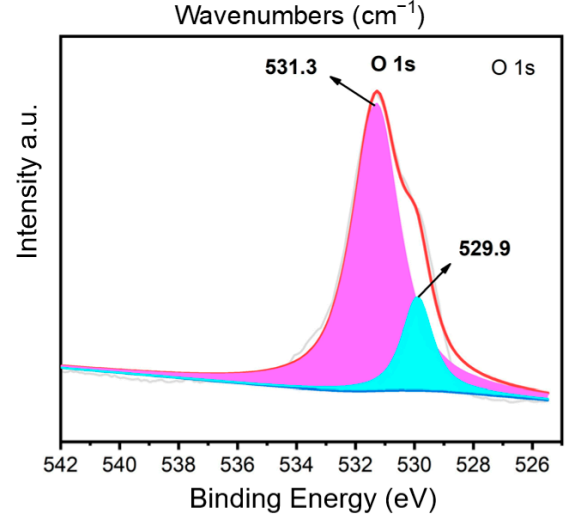

Figure 1. Characterizations of LBPIC. (a) SEM image, (b) FT-IR spectral analysis, XPS spectra for (c) the Fe $2 p$ region and (d) the $\mathrm{O} 1$ s region of prepared LBPIC.

FT-IR spectroscopy was performed to verify the synthesis of LBPIC. As shown in Figure $1 b$, the FT-IR spectra of LBP and LBPIC appeared to be similar, and several primary absorption peaks merely shifted to lower wavenumbers. The absorption band of LBP at $3421.7 \mathrm{~cm}^{-1}$, which is assignable to the stretching vibration of hydroxyl groups, shifted to $3417.8 \mathrm{~cm}^{-1}$ in the spectra of LBPIC [29]. The peaks of LBP at 1626.0 and $1072.4 \mathrm{~cm}^{-1}$ related to carboxyl groups shifted to 1618.3 and $1066.6 \mathrm{~cm}^{-1}$ in LBPIC, respectively, suggesting the involvement of carboxyl groups in the chelation [30,31]. In addition, the peaks of LBP at $2976.2,2929.9,1705.1$ and $1051.2 \mathrm{~cm}^{-1}$ distinctly vanished in the spectra of LBPIC. The bands at 2976.2 and $2929.9 \mathrm{~cm}^{-1}$ corresponded to $\mathrm{C}-\mathrm{H}$ asymmetric stretching vibrations, while the band at $1705.1 \mathrm{~cm}^{-1}$ was related to aldehyde carbonyl groups [32,33]. The band at $1051.2 \mathrm{~cm}^{-1}$ was possibly linked with the crystalline phases of LBP [34]. In addition, a broad 
shoulder occurred at $553.6-474.5 \mathrm{~cm}^{-1}$ in the fingerprint region of LBPIC compared to LBP, which might be a result of the significant enhancement of absorption peaks associated with iron oxides [32]. The information above indicated that the added iron ions tended to form iron oxides and that the coordination reaction between iron oxides and polysaccharides mainly occurred on the carboxyl groups, carbonyl groups and hydroxyl groups of LBP, which is in accordance with the idea that the iron in LBPIC exists in the form of iron oxides and that LBP serves as a ligand for the iron core complex.

To determine the concrete states of the surface constituent elements of LBPIC, the XPS spectra of LBPIC were analyzed. First, based on the peaks in Figure S3, it was determined that LBPIC mainly consisted of $\mathrm{C}, \mathrm{O}, \mathrm{N}$ and Fe. A previous report on the monosaccharide formation of LBP validated the existence of mannose, rhamnose, xylose, galactose and glucose in the chemical constitution of LBP [35]. In addition, amino residues are also involved in the glycoconjugates, which contributed to the peaks of $\mathrm{C} 1 \mathrm{~s}$ at $285.0 \mathrm{eV}, \mathrm{O}$ 1 s at $530.9 \mathrm{eV}, \mathrm{N}$ 1s at $399.5 \mathrm{eV}$ and Fe $2 \mathrm{p}$ at $711.2 \mathrm{eV}$. As shown in Figure 1c, there were five principal peaks in the high resolution XPS spectrum of Fe 2p. One satellite peak was observed at $719.0 \mathrm{eV}$, the other was at $733.0 \mathrm{eV}$, and the binding energy peaks at $711.0 \mathrm{eV}$ and $711.5 \mathrm{eV}$, which belong to $\mathrm{Fe} 2 \mathrm{p}^{3 / 2}$, corresponded to $\mathrm{FeOOH}[36,37]$. Then, the peak at $724.7 \mathrm{eV}$, attributed to $\mathrm{Fe} 2 \mathrm{p}^{1 / 2}$, was assigned to the characteristic peaks of iron (III) [38]. Moreover, two peaks at $529.9 \mathrm{eV}$ and $531.3 \mathrm{eV}$ were showed in the $\mathrm{O} 1 \mathrm{~s}$ XPS spectrum (Figure 1d), which were due to $\mathrm{Fe}-\mathrm{O}-\mathrm{Fe}$ and $\mathrm{Fe}-\mathrm{O}-\mathrm{H}$, respectively [39]. This result, together with the phenomenon of enhancement of peak absorption in the FT-IR spectra fingerprint region of LBPIC, is corroborative evidence of the existence of iron oxides in LBPIC. According to these results, a chelate composed of LBP and iron oxides was synthesized as expected.

To investigate the compositions and microstructures of LBPIC, XRD was performed, and the results are displayed in Figure S4. There were no sharp peaks in the pattern, indicating that LBPIC was classified as an amorphous material, which is in accord with its appearance. The weak diffraction peaks at $33.5^{\circ}$ and $56.0^{\circ}$ were ascribed to $\mathrm{FeOOH}$, which confirmed the existence of $\mathrm{FeOOH}$ in LBPIC, together with the signals corresponding to $\mathrm{FeOOH}$ in XPS. The weak peak at $43.3^{\circ}$ was attributed to a compound with iron (III) [40,41]. In certain circumstances, the bonding reaction between iron (III) and the hydroxyl groups of polysaccharides is able to weaken the hydrogen bonds in polysaccharides, leading to the poor absorption peak phenomena of polysaccharide-iron (III) complexes [42]. In addition, the molecular weights and components of polysaccharide material also affect the crystallinity of polysaccharide-iron (III) complexes. As mentioned above, the LBP material is composed of at least five kinds of monosaccharides. LBPIC, with poor homogeneity in its polysaccharide composition, is unlikely to crystallize [25]. All these characterization results demonstrated that an original LBPIC was successfully synthesized via a chemical method.

\subsection{Peroxidase-Like Activity of LBPIC}

To investigate the peroxidase-like activity of LBPIC, a typically used TMB $/ \mathrm{H}_{2} \mathrm{O}_{2}$ colorimetric assay was performed at room temperature. TMB is a chromogen extensively used in color-developing methods based on peroxidases. Under acidic conditions, colorless TMB was oxidized to blue ox-TMB in the presence of $\mathrm{H}_{2} \mathrm{O}_{2}$, resulting in an increase in the maximum absorbance at $652 \mathrm{~nm}$ (Figure S5). The POD-like activity of LBPIC is presented in Figure 2a. After reaction for the same period of time, $\mathrm{H}_{2} \mathrm{O}_{2}$ was catalyzed to generate $\bullet \mathrm{OH}$ radicals by LBPIC, which gave rise to the distinct increase in system absorbance [43]. By comparison, the absorbance change of $\mathrm{H}_{2} \mathrm{O}_{2}$ with TMB or TMB alone was minor. Of note, an earlier report showed that organic modified $\mathrm{FeOOH}$ had an excellent peroxidase activity [44], and the existence of FeOOH in LBPIC was also certified by this characterization. Therefore, we could infer that LBPIC possessed prominent POD-like activity, which was endowed by its inner FeOOH in all probability. 

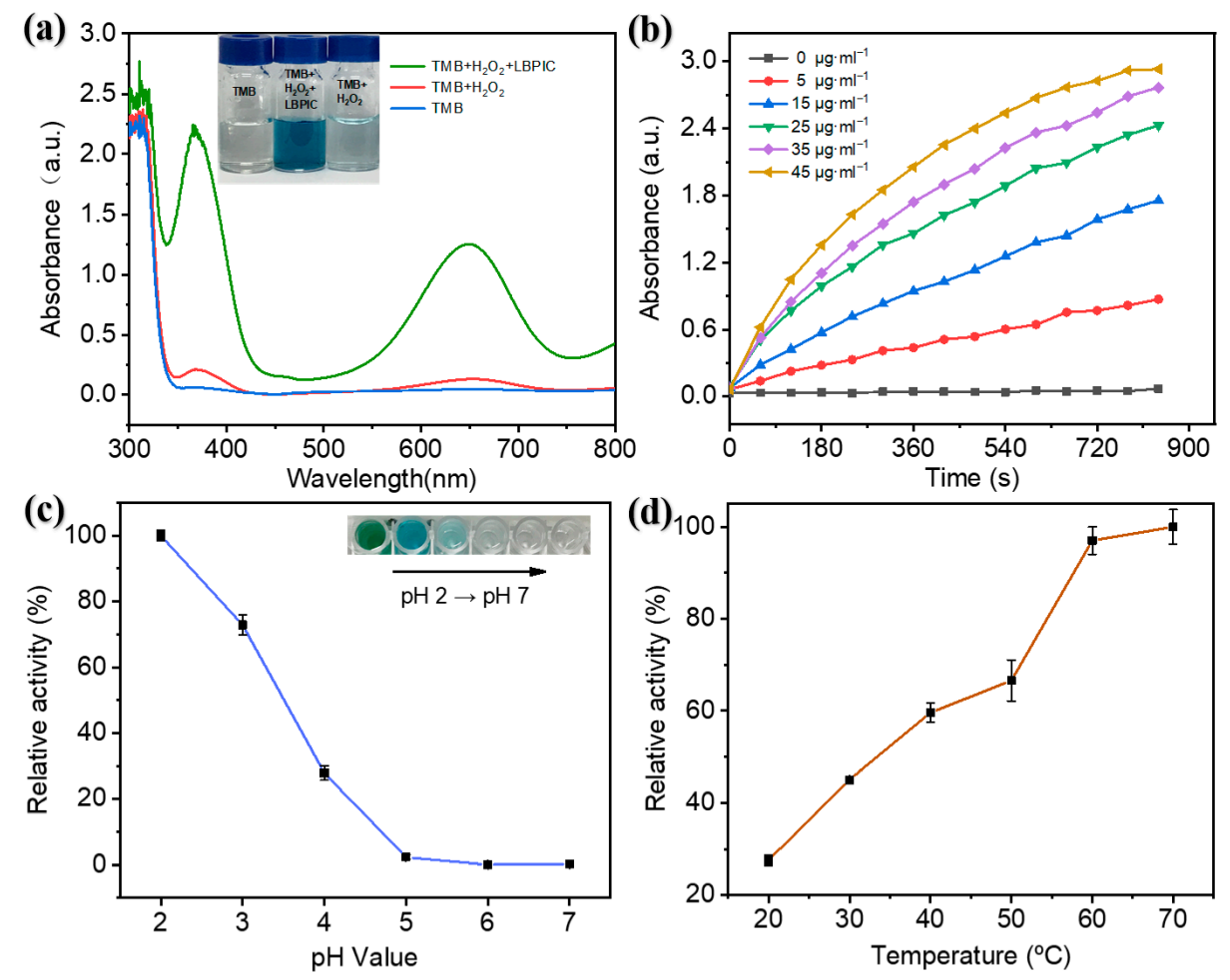

Figure 2. Peroxidase-like activity of LBPIC. (a) The UV-vis spectra and visual color of TMB in different system (b) the time-dependent absorbance spetra with different concentrations of LBPIC $(0-45 \mu \mathrm{g} / \mathrm{mL})$, peroxidase-like catalytic activity of LBPIC under (c) different $\mathrm{pH}(2-7)$ and (d) different temperature $\left(20-70{ }^{\circ} \mathrm{C}\right)$ in acetate buffer $(0.01 \mathrm{M}, \mathrm{pH} 3.0)$.

Figure $2 \mathrm{~b}$ shows that the reaction rate was accelerated as the concentration of LBPIC in the system increased. Clearly, the material dosage of $25 \mu \mathrm{g} / \mathrm{mL}$ allowed for both a high reaction velocity and economization of the material. Previous studies have shown that the catalytic activity of enzymes usually relies on $\mathrm{pH}$ and temperature. Consequently, multiple variations of the reaction environment, including buffers with different $\mathrm{pH}$ values (2-7), different temperatures $\left(20-70{ }^{\circ} \mathrm{C}\right)$ and time-dependent absorbance changes of different dosages of LBPIC $(0-45 \mu \mathrm{g} / \mathrm{mL})$, were assessed to optimize the parameters of the subsequent enzymatic chromogenic reactions with the participation of LBPIC. As shown in Figure $2 c, d$, the absorbance value of each reaction system was closely associated with the determinate $\mathrm{pH}$ value, suggesting a distinct variation trend of the enzymatic activity along with the stated $\mathrm{pH}$ value. The enzymatic activity of LBPIC increased monotonically as the $\mathrm{pH}$ decreased, while the activity increased stepwise as the temperature rose. Obviously, there was no occurrence of the turning point on the curves, which revealed that the catalytic activity of LBPIC did not exhibit representative inflexion within the established range of conditions.

Notably, TMB seemed to turn green after incubation. To the best of our knowledge, the oxidation of the TMB substrate was conducted under fairly strong acidic conditions in most cases, and the color of TMB was correlated with its structure. In the optimization test for $\mathrm{pH}$, the amino group on one side of TMB was oxidized when the $\mathrm{pH}$ value of the back buffer was in the range of 3.0-7.0, which resulted in the generation of blue ox$\mathrm{TMB}$ and presented a linear relationship between the concentrations of ox-TMB and the absorbance values at $652 \mathrm{~nm}$ of the corresponding reaction systems. However, if the test was performed in buffer whose $\mathrm{pH}$ was below 1.0, the amino groups on both sides of TMB would be affected, and the resultant TMB in diamine form would lead to a yellow color change in the mixture [45]. With the test $\mathrm{pH}$ value regulated to 2.0, ox-TMB and the diamine form of TMB were blended after the chromogenic reaction in the system to yield a reaction mixture that was seemingly green, a hybrid color of blue and yellow. It 
was not clear whether the conversion of ox-TMB to the diamine form of TMB influenced its absorbance at $652 \mathrm{~nm}$, which might cause deviation in the calculation. Consequently, in consideration of the color transition of TMB at $\mathrm{pH}$ 2.0, the conditions of the POD-like reaction were set at $\mathrm{pH} 3.0$ and room temperature after optimization, both for the accuracy and convenience of experiments.

\subsection{Steady-State Kinetics}

To obtain the kinetic constants of LBPIC, including $\mathrm{K}_{\mathrm{m}}$ and $\mathrm{V}_{\max }$, a steady-state kinetics study was carried out by varying the concentration of substrate TMB under a constant $\mathrm{H}_{2} \mathrm{O}_{2}$ concentration or vice versa at room temperature.

$$
\mathrm{v}=\mathrm{V}_{\max } \times[\mathrm{S}] /\left(\mathrm{K}_{\mathrm{m}}+[\mathrm{S}]\right)
$$

In the Michaelis-Menten equation, shown above, $\mathrm{v}$ is the initial reaction velocity and $[S]$ is the concentration of substrate. The absorbance data were transformed into concentrations according to the molar absorption coefficient of ox-TMB $\left(39,000 \mathrm{M}^{-1} \mathrm{~cm}^{-1}\right)$.

Typical Michaelis-Menten curves and Lineweaver-Burk double reciprocal plots are shown in Figure $3 a-d$, and the enzymatic kinetic constants $K_{m}$ and $V_{\max }$ were calculated. The $\mathrm{K}_{\mathrm{m}}$ of an enzyme is closely linked with its affinity to the substrate, and an enzyme with stronger affinity to its substrate usually has a smaller value of $\mathrm{K}_{\mathrm{m}}$. After calculation and fitting, the $\mathrm{K}_{\mathrm{m}}$ values of LBPIC toward $\mathrm{H}_{2} \mathrm{O}_{2}$ and TMB were $5.54 \mathrm{mM}$ and $0.16 \mathrm{mM}$, respectively, and the corresponding $\mathrm{V}_{\max }$ values were $35.79 \times 10^{-8} \mathrm{mM} \cdot \mathrm{s}^{-1}$ and $32.21 \times 10^{-8} \mathrm{mM} \cdot \mathrm{s}^{-1}$, respectively. Compared with HRP, LBPIC had a significantly higher affinity for TMB, and the maximum catalytic reaction velocities of LBPIC with $\mathrm{H}_{2} \mathrm{O}_{2}$ and TMB were apparently higher than that of HRP. Furthermore, the affinity of LBPIC for TMB was also higher than that of some metal-derived and carbon-derived nanozymes (Table S1). The results of these experiments affirmed that LBPIC was competent as a safe artificial peroxidase.
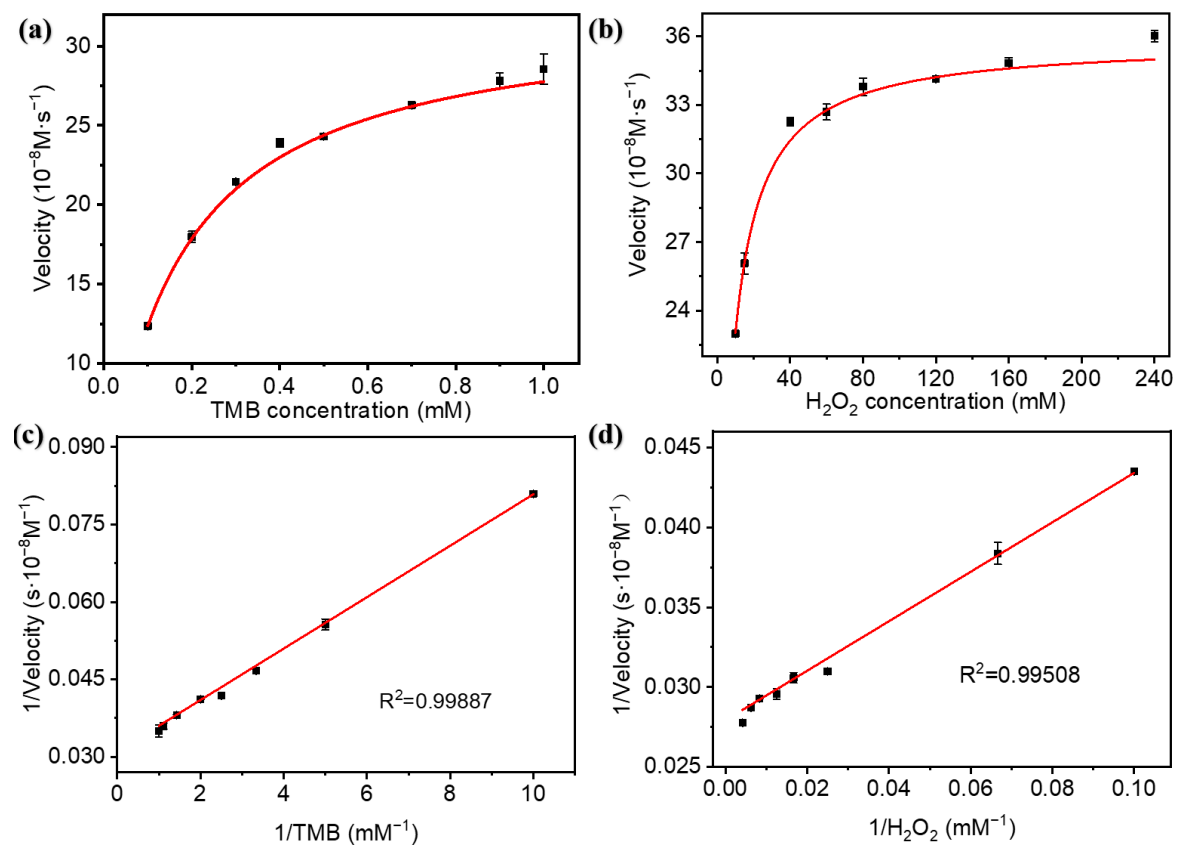

Figure 3. Steady-state kinetic analysis of LBPIC as a peroxidase mimetic. Michaelis-Menten curve of LBPIC with (a) TMB (0.1-1.0 mM) and (b) $\mathrm{H}_{2} \mathrm{O}_{2}$ (10-240 mM). Lineweaver-Burk plots of LBPIC with (c) TMB and (d) $\mathrm{H}_{2} \mathrm{O}_{2}$ in acetate buffer $(0.01 \mathrm{M}, \mathrm{pH} 3.0)$ at room temperature. 


\subsection{Colorimetric Detection of $A A$}

AA, which is one of the antioxidants that commonly occurs in foods, is not only used to extend the shelf life but also to guarantee the pleasing presentation, unique flavors and delicate mouthfeel of foods. The blue ox-TMB can be reduced to colorless TMB by AA due to its reducibility. Here, a colorimetric detection assay for AA based on the POD-like activity of LBPIC was successfully constructed. The test conditions were determined to be $\mathrm{pH} 3.0$ and room temperature, and the reaction systems were incubated for $180 \mathrm{~s}$ after the addition of a series of concentrations of AA.

Subsequently, as shown in Figure $4 \mathrm{a}, \mathrm{b}$, with the increase in the concentration of additional AA, the bleaching degree of colorimetric systems increased accordingly. After linear fitting of the data, there was a remarkable linear negative correlation $\left(R^{2}=0.99909\right)$ between the absorbance of the mixture at $652 \mathrm{~nm}$ and the concentration of $\mathrm{AA}$, and the linear range was 2-100 $\mu \mathrm{M}$. In addition, the LOD (limit of detection) of this method was $1.51 \mu \mathrm{M}$, referring to the $3 \mathrm{~S} / \mathrm{N}$ (signal/noise) equation. Compared with some previous AA detection assays based on nanozymes, the TMB $/ \mathrm{H}_{2} \mathrm{O}_{2} /$ LBPIC system provided a preferable LOD and linear range, and the incubation time of the assay was significantly shorter than that of other methods (Table S2), which could dramatically accelerate AA determination for food samples.
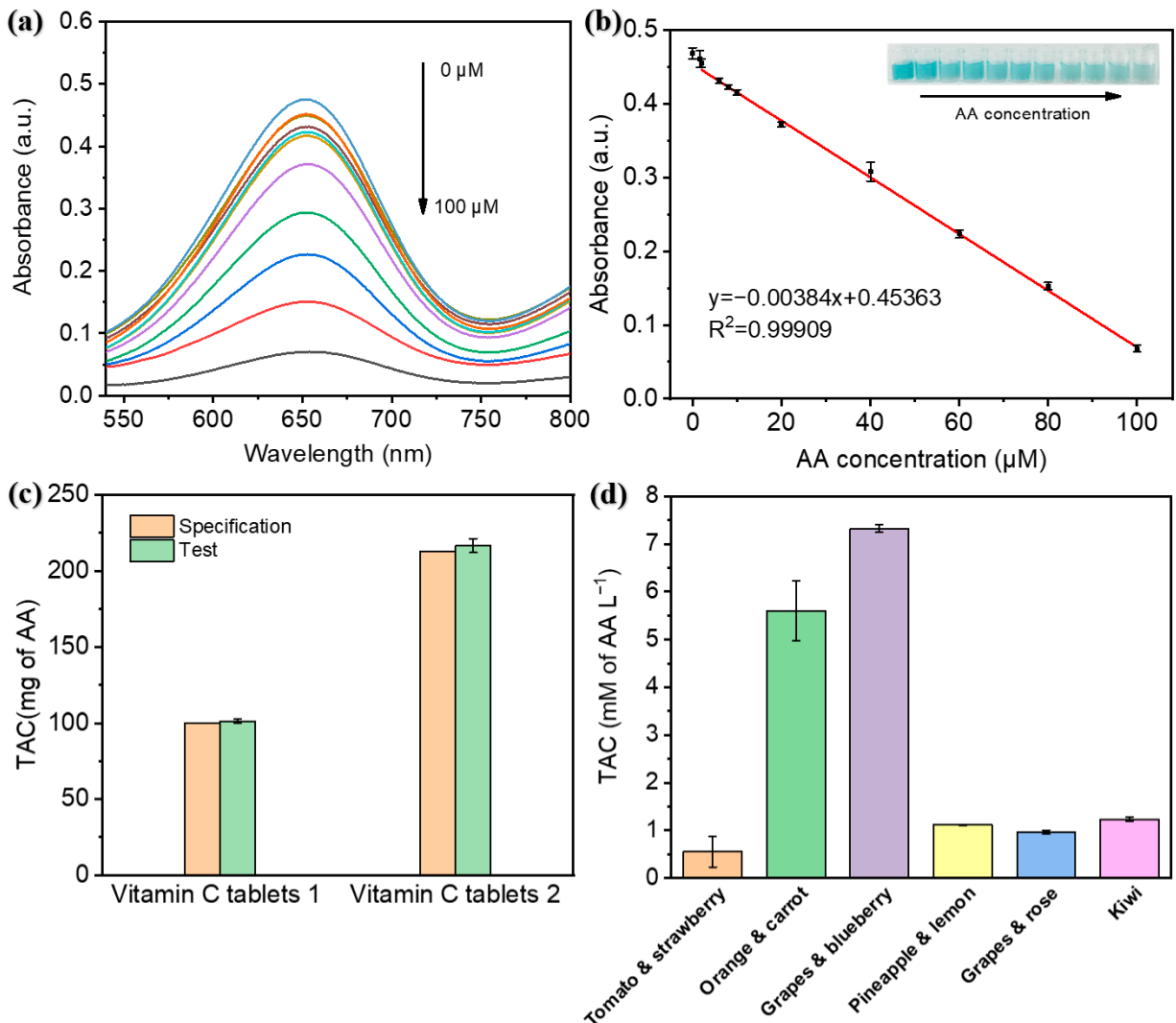

Figure 4. Total antioxidant capacity colorimetric assay using AA as a typical antioxidant model. (a) AA concentration-dependent UV-vis absorbance spectra. (b) Linear plots of system absorbance at $652 \mathrm{~nm}$ versus concentrations of AA, the inset shows the linear calibration plots for AA detection. (c) Verification experiment for the accuracy of TAC assay using two vitamin C tablets. (d) TAC of tomato \& strawberry, orange \& carrot, grapes \& blueberry, pineapple \& lemon, grapes \& rose compound beverages and kiwi fermented beverage.

The constituent analysis of most food samples is usually regarded as tedious work due to the complicated ingredients of food itself, which have a nonnegligible impact on the detection signal. Therefore, the analytical method for food samples ought to be capable 
of withstanding certain interferences. To further explore the selectivity of the established colorimetric detection assay for AA, five kinds of metal ions $\left(\mathrm{Mg}^{2+}, \mathrm{Ca}^{2+}, \mathrm{Zn}^{2+}, \mathrm{Na}^{+}\right.$and $\mathrm{K}^{+}$), four kinds of amino acids (alanine, glutamic acid, aspartic acid and glycine), two kinds of disaccharides (fructose and sucrose) and citric acid were used as interference factors. The selected interference factors at given concentrations were added to the chromogenic system, while the control group was carried out by adding AA.

As illustrated in Figure S6, the ox-TMB in the control group was completely bleached. The influences on the color system caused by the interference factors listed were not above $5 \%$ according to the comparison between the absorbances of the blank group and the interference test groups. The chromogenic results of test groups were not visibly affected, even though the concentrations of interference factors were 20 times that of AA. In short, the colorimetric assay based on the $\mathrm{TMB} / \mathrm{H}_{2} \mathrm{O}_{2} / \mathrm{LBPIC}$ system has the features of rapid detection, a wide detection range and good selectivity.

\subsection{TAC Assay}

As an indicator to evaluate the nutritional value of food, the TAC, which was determined by the colorimetric AA detection assay, was expressed as micromoles of AA/L. In this study, five kinds of commercial compound fruit and vegetable beverages and one fermented beverage of kiwi, both cloudy and clear types, were selected as testing samples. The compound beverages, including tomato and strawberry, orange and carrot, and grape and blueberry, represented cloudy-type juice, while the other two compound beverages represented clear-type juice. Before the analysis, each beverage was diluted to an appropriate concentration with distilled water to meet two fundamental criteria: (1) the diluted sample was approximately colorless and transparent for the purpose of excluding the interferences resulting from pigments and insoluble beverages, which might make a difference in the results of colorimetric determination; (2) the absorbance of the reaction mixture after chromogenesis was distributed within the linear range of the AA detection method. As shown in Figure 4c, to verify the accuracy of the TAC assay, the TAC of two vitamin $C$ tablets was measured. The test results were in accordance with the AA content in the vitamin $C$ tablets, demonstrating that the TAC assay proposed by us can be used for practical samples on the basis of its high accuracy, good selectivity and convenient operation [46].

As shown in Figure $4 d$, the results of the test groups revealed that the TAC values of the orange \& carrot and grape \& blueberry beverages were significantly higher than those of the pineapple \& lemon and grape \& rose beverages, illustrating that the antioxidant capacity of compound fruit and vegetable beverages of the cloudy type were generally greater [47]. To summarize, the TAC assay based on the TMB $/ \mathrm{H}_{2} \mathrm{O}_{2} / \mathrm{LBPIC}$ system was shown to be feasible, which expands the use of chelates based on polysaccharides in food analysis.

\section{Conclusions}

In summary, crude polysaccharide from Lycium barbarum was purified and decolored, and processed Lycium barbarum polysaccharide, sodium citrate and ferric trichloride were used to prepare a novel Lycium barbarum polysaccharide-iron (III) chelate through a convenient and energy-efficient synthesis procedure. Afterward, the product was characterized, and its peroxidase-like activity was studied by means of the $\mathrm{TMB} / \mathrm{H}_{2} \mathrm{O}_{2}$ chromogenic system. LBPIC displayed superior peroxidase-like activity with a $\mathrm{K}_{\mathrm{m}}$ of $5.54 \mathrm{mM}$ for $\mathrm{H}_{2} \mathrm{O}_{2}$ and $0.16 \mathrm{mM}$ for TMB. Finally, a TAC assay with a wide linear range of 2-100 $\mu \mathrm{M}$ was built on the basis of the TMB $/ \mathrm{H}_{2} \mathrm{O}_{2}$ /LBPIC system, and AA was used as a practical antioxidant intermediary. In addition, the TAC values of six different commercial beverages were successfully assessed via the constructed colorimetric method. LBPIC, with the advantages of high POD-like activity, high biological security, mild preparation conditions and easily obtained materials, demonstrates good prospects for the fields of 
food analysis and organic biosensors and also forms the basis of an original application for polysaccharide-iron complexes.

Supplementary Materials: The following are available online at https:/ /www.mdpi.com/article/10 .3390/foods10112800/s1, Section 1: Preparation of material Lycium barbarum polysaccharide (LBP), Section 2: Characterization of LBP-iron (III) chelate (LBPIC), Section 3: Optimization for the test conditions of peroxidase-like activity of LBPIC, Figure S1: LBPIC (Lycium barbarum polysaccharideiron(III) chelate) powder, Figure S2: Storage stability test of LBPIC in water solution $(1.0 \mathrm{mg} / \mathrm{mL})$ for a week, Figure S3: XPS spectrum of LBPIC, Figure S4: XRD spectrum of LBPIC, Figure S5: The color change mechanism of $\mathrm{TMB} / \mathrm{H}_{2} \mathrm{O}_{2}$ system, Figure $\mathrm{S6}$ : Selectivity analysis of AA over some common interfering substances coexisting in commercial compound fruit and vegetable beverages, Table S1: The kinetic parameters of LBP-iron (III) chelate and some other peroxidase mimetics with TMB and $\mathrm{H}_{2} \mathrm{O}_{2}$ as substrates. Table S2: Comparison of different materials for the detection of AA.

Author Contributions: Conceptualization, S.S.; methodology, S.S. and W.Z.; resources, S.S.; software, S.S., L.L. and J.F.; validation, S.S., J.F., Y.L., H.S. and Z.S.; formal analysis, J.F., X.Y. and W.Z.; investigation, S.S., W.Z. and J.F.; data curation, J.F.; writing—original draft preparation, S.S. and J.F.; writing-review and editing, S.S., W.Z. and J.F; visualization, X.Y. and J.F.; supervision, J.W. and W.Z. All authors have read and agreed to the published version of the manuscript.

Funding: This research was funded by the National Science Foundation of China $(21675127,31901794)$, the National Postdoctoral Program for Innovative Talents (BX20180263), the China Postdoctoral Science Foundation (2018M641026), the Shaanxi Provincial Science Fund for Distinguished Young Scholars (2018JC-011), and the Young Talent Fund of University Association for Science and Technology in Shaanxi, China (2019-02-03), the Key Research and Development Program of Shaanxi Province (2019NY-111), and the Tang Scholar by Cyrus Tang Foundation.

Institutional Review Board Statement: Not applicable.

Informed Consent Statement: Not applicable.

Data Availability Statement: The data presented in this study are available on request from the corresponding author.

Acknowledgments: Graphic abstract and Scheme 1 were modified from Servier Medical Art (http://smart.servier.com/, accessed date: 27 August 2021), licensed under a Creative Common Attribution 3.0 Generic License (https:/ / creativecommons.org/licenses/by/3.0/, accessed date: 27 August 2021).

Conflicts of Interest: The authors declare no conflict of interest.

\section{Abbreviations}

LBP Lycium barbarum polysaccharide

LBPIC Lycium barbarum polysaccharide-iron (III) chelate

TAC total antioxidant capacity

POD peroxidase

TMB 3,3',5, $5^{\prime}$-tetramethyl-benzidine

$\mathrm{H}_{2} \mathrm{O}_{2} \quad$ hydrogen peroxide

AA ascorbic acid

LOD limit of detection

HRP horseradish peroxidase

ROS reactive oxygen species

OS oxidative stress

EPR electron paramagnetic resonance

ATR-IR attenuated total reflectance infrared spectroscopy

DPPH 2,2'-diphenyl-1-picrylhydrazyl

ABTS 2,2-azinobis-(3-ethylbenzothiazoline-6-sulfonate)

ORAC oxygen radical absorbance capacity

FC Folin-Ciocalteu 


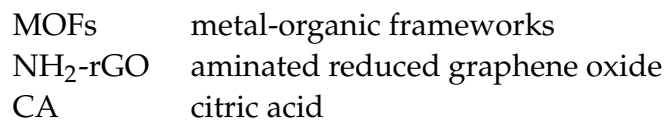

\section{References}

1. Sies, H.; Jones, D.P. Reactive oxygen species (ROS) as pleiotropic physiological signalling agents. Nat. Rev. Mol. Cell Bio. 2020, 21, 363-383. [CrossRef]

2. Neha, K.; Haider, M.R.; Pathak, A.; Yar, M.S. Medicinal prospects of antioxidants: A review. Eur. J. Med. Chem. 2019, 178, 687-704. [CrossRef]

3. Cömert, E.D.; Gökmen, V. Antioxidants bound to an insoluble food matrix: Their analysis, regeneration behavior, and physiological importance. Compr. Rev. Food Sci. Food Saf. 2017, 16, 382-399. [CrossRef]

4. Cömert, E.D.; Gökmen, V. Evolution of food antioxidants as a core topic of food science for a century. Food Res. Int. 2018, 105, 76-93. [CrossRef] [PubMed]

5. Pellegrini, N.; Vitaglione, P.; Granato, D.; Fogliano, V. Twenty-five years of total antioxidant capacity measurement of foods and biological fluids: Merits and limitations. J. Sci. Food Agric. 2020, 100, 5064-5078. [CrossRef]

6. Polak, J.; Bartoszek, M. The study of antioxidant capacity of varieties of nalewka, a traditional Polish fruit liqueur, using EPR, NMR and UV-vis spectroscopy. J. Food Compos. Anal. 2015, 40, 114-119. [CrossRef]

7. Wu, Z.Z.; Xu, E.B.; Long, J.; Pan, X.W.; Xu, X.M.; Jin, Z.Y.; Jiao, A.Q. Comparison between ATR-IR, Raman, concatenated ATR-IR and Raman spectroscopy for the determination of total antioxidant capacity and total phenolic content of Chinese rice wine. Food Chem. 2016, 194, 671-679. [CrossRef]

8. Andrei, V.; Bunea, A.-I.; Tudorache, A.; Gáspár, S.; Vasilescu, A. Simple DPPH.-based electrochemical assay for the evaluation of the antioxidant capacity: A thorough comparison with spectrophotometric assays and evaluation with real-world samples. Electroanalysis 2014, 26, 2677-2685. [CrossRef]

9. Floegel, A.; Kim, D.O.; Chung, S.J.; Koo, S.I.; Chun, O.K. Comparison of ABTS/DPPH assays to measure antioxidant capacity in popular antioxidant-rich US foods. J. Food Compos. Anal. 2011, 24, 1043-1048. [CrossRef]

10. Iranifam, M.; Al Lawati, H.A.J. Monitoring the antioxidant capacity in honey and fruit juices using a microfluidic device with a $\mathrm{NaHCO}_{3}-\mathrm{H}_{2} \mathrm{O}_{2}-\mathrm{Co}^{2+}$ chemiluminescence reaction. Food Chem. 2019, 297, 124930. [CrossRef]

11. Gillespie, K.M.; Chae, J.M.; Ainsworth, E.A. Rapid measurement of total antioxidant capacity in plants. Nat. Protoc. 2007, 2, 867-870. [CrossRef]

12. Wei, H.; Wang, E. Nanomaterials with enzyme-like characteristics (nanozymes): Next-generation artificial enzymes. Chem. Soc. Rev. 2013, 42, 6060-6093. [CrossRef]

13. Berglund, G.I.; Carlsson, G.H.; Smith, A.T.; Szoke, H.; Henriksen, A.; Hajdu, J. The catalytic pathway of horseradish peroxidase at high resolution. Nature 2002, 417, 463-468. [CrossRef]

14. Chen, Z.W.; Yin, J.J.; Zhou, Y.T.; Zhang, Y.; Song, L.; Song, M.J.; Hu, S.L.; Gu, N. Dual enzyme-like activities of iron oxide nanoparticles and their implication for diminishing cytotoxicity. ACS Nano 2012, 6, 4001-4012. [CrossRef]

15. Wang, Q.; Zhang, X.; Huang, L.; Zhang, Z.; Dong, S. One-pot synthesis of $\mathrm{Fe}_{3} \mathrm{O}_{4}$ nanoparticle loaded 3D porous graphene nanocomposites with enhanced nanozyme activity for glucose detection. ACS Appl. Mater. Interfaces 2017, 9, 7465-7471. [CrossRef] [PubMed]

16. Gao, L.; Fan, K.; Yan, X. Iron oxide nanozyme: A multifunctional enzyme mimetic for biomedical applications. Theranostics 2017, 7, 3207-3227. [CrossRef] [PubMed]

17. Liang, H.; Liu, B.; Yuan, Q.; Liu, J. Magnetic iron oxide nanoparticle seeded growth of nucleotide coordinated polymers. ACS Appl. Mater. Interfaces 2016, 8, 15615-15622. [CrossRef] [PubMed]

18. Wu, Y.; Jiao, L.; Luo, X.; Xu, W.; Wei, X.; Wang, H.; Yan, H.; Gu, W.; Xu, B.Z.; Du, D.; et al. Oxidase-like Fe-N-C single-atom nanozymes for the detection of acetylcholinesterase activity. Small 2019, 15, 1903108. [CrossRef] [PubMed]

19. Xu, W.; Kang, Y.; Jiao, L.; Wu, Y.; Yan, H.; Li, J.; Gu, W.; Song, W.; Zhu, C. Tuning atomically dispersed Fe sites in metal-organic frameworks boosts peroxidase-like activity for sensitive biosensing. Nano-Micro Lett. 2020, 12, 184. [CrossRef]

20. London, E. The molecular formula and proposed structure of the iron-dextran complex, imferon. J. Pharm. Sci. 2004, 93, 1838-1846. [CrossRef]

21. Boury, B.; Plumejeau, S. Metal oxides and polysaccharides: An efficient hybrid association for materials chemistry. Green Chem. 2015, 17, 72-88. [CrossRef]

22. Tian, X.; Liang, T.; Liu, Y.; Ding, G.; Zhang, F.; Ma, Z. Extraction, structural characterization, and biological functions of Lycium barbarum polysaccharides: A Review. Biomolecules 2019, 9, 389. [CrossRef]

23. Chen, Y.; Jiao, L.; Yan, H.; Xu, W.; Wu, Y.; Wang, H.; Gu, W.; Zhu, C. Hierarchically porous S/N co-doped carbon nanozymes with enhanced peroxidase-like activity for total antioxidant capacity biosensing. Anal. Chem. 2020, 92, 13518-13524. [CrossRef]

24. Shi, S.; Zhang, W.; Liu, X.; Ren, X.; Li, M.; Sun, J.; Wang, Y.; Yue, T.; Wang, J. A sustainable and nondestructive method to high-throughput decolor Lycium barbarum L. polysaccharides by graphene-based nano-decoloration. Food Chem. 2021, 338, 127749. [CrossRef]

25. Zhang, J.Q.; Chen, C.; Fu, X. Fructus mori L. polysaccharide-iron chelates formed by self-embedding with iron (III) as the core exhibit good antioxidant activity. Food Funct. 2019, 10, 3150-3160. [CrossRef] [PubMed] 
26. Lou, Z.P.; Zhao, S.; Wang, Q.; Wei, H. N-Doped carbon as peroxidase-like nanozymes for total antioxidant capacity assay. Anal. Chem. 2019, 91, 15267-15274. [CrossRef]

27. Liu, T.; Liu, T.; Liu, H.; Fan, H.; Chen, B.; Wang, D.; Zhang, Y.; Sun, F. Preparation and characterization of a novel polysaccharideiron (III) complex in Auricularia auricula potentially used as an iron supplement. BioMed Res. Int. 2019, 2019, 6416941. [CrossRef] [PubMed]

28. Zhang, X.; Zhang, X.; Gu, S.; Pan, L.; Sun, H.; Gong, E.; Zhu, Z.; Wen, T.; Daba, G.M.; Elkhateeb, W.A. Structure analysis and antioxidant activity of polysaccharide-iron (III) from Cordyceps militaris mycelia. Int. J. Biol. Macromol. 2021, 178, 170-179. [CrossRef] [PubMed]

29. Chi, Y.Z.; Li, Y.P.; Zhang, G.L.; Gao, Y.Q.; Ye, H.; Gao, J.; Wang, P. Effect of extraction techniques on properties of polysaccharides from Enteromorpha prolifera and their applicability in iron chelation. Carbohydr. Polym. 2018, 181, 616-623. [CrossRef] [PubMed]

30. Lu, Q.; Xu, L.; Meng, Y.; Liu, Y.; Li, J.; Zu, Y.; Zhu, M. Preparation and characterization of a novel Astragalus membranaceus polysaccharide-iron (III) complex. Int. J. Biol. Macromol. 2016, 93, 208-216. [CrossRef] [PubMed]

31. Gao, W.H.; Huang, Y.P.; He, R.X.; Zeng, X.A. Synthesis and characterization of a new soluble soybean polysaccharide-iron (III) complex using ion exchange column. Int. J. Biol. Macromol. 2018, 108, 1242-1247. [CrossRef] [PubMed]

32. Wang, K.P.; Chen, Z.X.; Zhang, Y.; Wang, P.P.; Wang, J.H.; Dai, L.Q. Molecular weight and proposed structure of the Angelica sinensis polysaccharide-iron complex. Chin. J. Chem. 2008, 26, 1068-1074. [CrossRef]

33. Ganie, S.A.; Naik, R.A.; Ali, A.; Mir, T.A.; Mazumdar, N. Preparation, characterization, release and antianemic studies of guar gum functionalized iron complexes. Int. J. Biol. Macromol. 2021, 183, 1495-1504. [CrossRef] [PubMed]

34. Wang, J.; Chen, H.; Wang, Y.; Xing, L. Synthesis and characterization of a new Inonotus obliquus polysaccharide-iron (III) complex. Int. J. Biol. Macromol. 2015, 75, 210-217. [CrossRef] [PubMed]

35. Wu, H.T.; He, X.J.; Hong, Y.K.; Ma, T.; Xu, Y.P.; Li, H.H. Chemical characterization of Lycium barbarum polysaccharides and its inhibition against liver oxidative injury of high-fat mice. Int. J. Biol. Macromol. 2010, 46, 540-543. [CrossRef] [PubMed]

36. Wu, P.F.; Zhou, C.L.; Li, Y.P.; Zhang, M.H.; Tao, P.X.; Liu, Q.L.; Cui, W.Q. Flower-like FeOOH hybridized with carbon quantum dots for efficient photo-Fenton degradation of organic pollutants. Appl. Surf. Sci. 2021, 540, 148362. [CrossRef]

37. Biesinger, M.C.; Payne, B.P.; Grosvenor, A.P.; Lau, L.W.M.; Gerson, A.R.; Smart, R.S. Resolving surface chemical states in XPS analysis of first row transition metals, oxides and hydroxides: Cr, Mn, Fe, Co and Ni. Appl. Surf. Sci. 2011, 257, 2717-2730. [CrossRef]

38. Ding, M.M.; Chen, W.; Xu, H.; Shen, Z.; Lin, T.; Hu, K.; Lu, C.H.; Xie, Z.L. Novel alpha-Fe ${ }_{2} \mathrm{O}_{3} / \mathrm{MXene}$ nanocomposite as heterogeneous activator of peroxymonosulfate for the degradation of salicylic acid. J. Hazard. Mater. 2020, 382, 121064. [CrossRef]

39. Wang, K.; Du, H.; He, S.; Liu, L.; Yang, K.; Sun, J.; Liu, Y.; Du, Z.; Xie, L.; Ai, W.; et al. Kinetically controlled, scalable synthesis of gamma-FeOOH nanosheet arrays on nickel foam toward efficient oxygen evolution: The key role of in-situ-generated gamma-NiOOH. Adv. Mater. 2021, 33, 2005587. [CrossRef]

40. Lu, W.; Duan, C.; Zhang, Y.; Gao, K.; Dai, L.; Shen, M.; Wang, W.; Wang, J.; Ni, Y. Cellulose-based electrospun nanofiber membrane with core-sheath structure and robust photocatalytic activity for simultaneous and efficient oil emulsions separation, dye degradation and Cr(VI) reduction. Carbohydr. Polym. 2021, 258, 117676. [CrossRef]

41. Li, W.F.; Ma, H.H.; Yuan, S.; Zhang, X.F. Production of Pyracantha polysaccharide-iron (III) complex and its biologic activity. Molecules 2021, 26, 1949. [CrossRef]

42. Wang, L.; Zhang, P.; Li, C.; Chen, J. Antioxidant and digestion properties of polysaccharides from Rosa roxburghii Tratt fruit and polysacchride-iron (III) complex. J. Food Process. Preserv. 2021, 45, e15617. [CrossRef]

43. Luo, L.; Huang, L.; Liu, X.; Zhang, W.; Yao, X.; Dou, L.; Zhang, X.; Nian, Y.; Sun, J.; Wang, J. Mixed-valence Ce-BPyDC metal-organic framework with dual enzyme-like activities for colorimetric biosensing. Inorg. Chem. 2019, 58, 11382-11388 [CrossRef]

44. Wang, L.J.; Xu, X.C.; Niu, X.H.; Pan, J.M. Colorimetric detection and membrane removal of arsenate by a multifunctional L-arginine modified FeOOH. Sep. Purif. Technol. 2021, 258, 118021. [CrossRef]

45. Frey, A.; Meckelein, B.; Externest, D.; Schmidt, M.A. A stable and highly sensitive 3,3' $5,5^{\prime}$-tetramethylbenzidine-based substrate reagent for enzyme-linked immunosorbent assays. J. Immunol. Methods 2000, 233, 47-56. [CrossRef]

46. Song, N.; Zhong, M.; Xu, J.; Wang, C.; Lu, X. Single-atom iron confined within polypyrrole-derived carbon nanotubes with exceptional peroxidase-like activity for total antioxidant capacity. Sens. Actuators B Chem. 2021, 351, 130969. [CrossRef]

47. Markowski, J.; Zbrzezniak, M.; Mieszczakowska-Frac, M.; Rutkowski, K.; Popinska, W. Effect of cultivar and fruit storage on basic composition of clear and cloudy pear juices. LWT Food Sci. Technol. 2012, 49, 263-266. [CrossRef] 